Research Article

\title{
Prevention and Control Technology for Harmful Toxic Gas Intrusion in High-Fire-Hazard-Risk Areas of Close-Distance Coal Seams
}

\author{
Wei Wang $\mathbb{D}^{1,2,3}$ and Yuntao Liang ${ }^{2,3}$ \\ ${ }^{1}$ Graduate School of China Coal Research Institute, Beijing 100013, China \\ ${ }^{2}$ State Key Laboratory of Coal Mine Safety Technology, Fushun 113122, China \\ ${ }^{3}$ CCTEG Shenyang Research Institute, Fushun 113122, China
}

Correspondence should be addressed to Wei Wang; wangwei@syccri.com

Received 14 August 2020; Revised 14 September 2020; Accepted 10 October 2020; Published 29 October 2020

Academic Editor: Tifeng Jiao

Copyright (C) 2020 Wei Wang and Yuntao Liang. This is an open access article distributed under the Creative Commons Attribution License, which permits unrestricted use, distribution, and reproduction in any medium, provided the original work is properly cited.

\begin{abstract}
Fire hazard-risk area in small coal pits can be found in the southern part of the Shigetai Coal Mine, a close-distance coal seam mining sector in the Shendong mining area, which is susceptible to the risk of harmful toxic gas intrusion, seriously threatening the safety of mining around the working surface. Aiming at this problem, a numerical model representing the mining activity on the close-distance coal seams was established to simulate the movement pattern of overlying strata and the development process of fractures based on the horizontal stress "normalization" technology. Also, the principal air-leak passageways were detected with the $\mathrm{SF}_{6}$ tracer analysis. On this basis, the influencing pattern of harmful toxic gas intruding into the working surface can be comprehensively analyzed, providing a basis for effectively preventing and controlling gas intrusion disasters. The research findings show that, after a lower coal seam has been mined, the caving zone ranges from $73 \mathrm{~m}$ to $94 \mathrm{~m}$ in height, and the fractured zone tends to develop all the way to the surface. Furthermore, shear fractures are the major passageways for air leakage, and the occurrence of gas intrusion disasters is basically taking place at the same time frame as the occurrence of roof weighting. Meanwhile, the harmful toxic gas intrudes the working surface through the fractures on the security coal pillars and shear fractures on the overlying strata. To prevent intrusion disasters from occurring, the applications of inorganic foaming and curing materials for filling were studied in combination with the actual engineering conditions. The construction grounds in sections where the fire hazard-risk area in small coal pits have not been stripped were drilled, and filling materials were poured into the goaf to create an isolation belt. As can be observed from the applied areas, constructing isolation belts to block the major air-leak passageways can effectively prevent the harmful toxic gases from intruding into the working surface, ensuring the safety of mining on the working surface.
\end{abstract}

\section{Introduction}

In recent years, the distribution of coal resource production capacity in China is gradually converging towards the advantaged regions, where the coal resource is naturally abundant, and the market competitiveness is high. As a result, the locus of production and development focus has also been shifting westward [1]. Close-distance coal seam mining on shallow burial depth is a common place in western China. For instance, there are 9 primary minable seams in the Shendong Mine, which lies about $70 \mathrm{~m}$ below the average surface. To be specific, the distance separating upper coal seam 12\# on the upper group and coal seam 52\# on the lower group is merely $170 \mathrm{~m}$ [2]. The coating layer is primarily made of quaternary thick alluvium and Cretaceous-Jurassic bedrock. With the completion of the exploitation of the primary mineable coal seams in the upper group, the mining activities in many of the mining sectors in the Shendong Mine are now being successively shifted into the mining sectors of the primary mineable coal seams in the 
lower group [3, 4]. The resulting coexistence of surface air leakage, interlayer air leakage, and air leakage in this layer has greatly increased the probability of spontaneous combustion by the residual coal in the goafs. A large number of small unwarranted pits can be found around parts of the mines in the western coal region; some are adjacent to or overlapping with larger mine fields, while others have seen overexploitation beyond their predetermined boundaries. The mining of small pits have also been largely disordered, causing the locations of interconnected small pit goafs to be erratically scattered. Furthermore, huge amounts of residual coals can still be found in the goafs, resulting in poor air circulation and oxidative spontaneous combustion. Signs of fire hazards have appeared in some of the small pits, while high-fire-hazard-risk areas have formed in others. As the mining continues in large mines, surface fractures become increasingly apparent, increasing the probability for small pits with low fire-hazard risks to develop into high-firehazard-risk areas $[5,6]$. Due to the high content of harmful toxic gases inside the small pits, the concealed locations of fire source, and the continued development of fracture in the coal seam strata, the highly concentrated harmful toxic gases in the small pits may pose severe threat to the mining activities conducted in the surrounding coal seams, bringing huge challenges to the fire-hazard-prevention staff in the mine pits $[7,8]$.

The formation of air-leak passageways from fracture development is a necessary precondition for the intrusion of harmful gases from the high-fire-hazard-risk areas into the working surface. Concerning the study of fracture development pattern, Miao [9] believes that the evolution of fractures on overburden rock strata is dependent upon structural ruptures and motion. On this basis, Miao proposed a quantitative description method for fracture distribution in overburden rock strata, including the dynamic distribution of longitudinal fractures and the dynamic evolution of abscission crevices, as well as the distribution pattern of the "O" ring. Chen and Zhu [10] pointed out that the formation mechanism of mining ground fissures formed by deep mining and high-intensity mining in ecologically fragile mining areas in the western China may be different from those resulted from traditional mining methods. Pan et al. [11] proposed a computation method for aggregate mining thickness applicable in close-distance mining of double-layered thick coal seams, as well as the formula for calculating the development of fracture zones associated with fully mechanized caving mining, ultimately revealing the air leakage mechanism along the ground surface, upper mining area, and lower mining area. Zeng et al. [12] determined the spatial range of different fracture areas in the coal fire control body and the calculation method for its air permeability according to the movement pattern of overlying rock strata amid the mining of coal seams. Fan et al. [13] analyzed the dynamic evolution characteristics of overlying rock strata movement as well as the expansion and distribution of fractures along the horizontal and vertical directions resulting from shallow burial depth long-coalseam-wall mining. Ma et al. [14] indicated that fractures can be formed on rock masses in a coalfield's high-fire-hazard- risk zone through thermal rupturing, which in turn provide passageways for air and pyrolysis gases, promoting the development of high-fire-hazard-risk areas, causing the overlying rock mass to collapse due to breakage or weight loss, eventually forming a complete coupling process involving thermal rupturing, air flow, solidification, and then breaking down. When it comes to searching the air-leak passageways, the energy level measurement and tracer technique was combined to jointly detect the air leakage state [15-17].

When the effects of harmful toxic gases in the high-firehazard-risk area become apparent, the open-area pressure equalization technology is generally adopted for prevention and control [18-20]. Nevertheless, before adopting the pressure equalization technology to create air flow, every technical parameter related to the air flow creation through the passageways nearby the high-fire-hazard-risk area needs to be well grasped. These parameters include the distribution of wind pressure, air flux magnitude, air leakage magnitude, the wind resistance in each passageway, and the network structure of the air flow passageways. In other words, high levels of technical and management expertise by the mine owner are required since once the pressure-regulating fan stops working, secondary disasters will readily occur. And no fan with automatic pressure adjustment is presently available. Besides, an automatic pressure-regulating fan has yet to exist, which means that it is currently impossible to reactively adapt the "pressure equalization" process based on the values of all other parameters, i.e., the current pressureregulation method is in itself a considerably "rash" approach. In general, the equal-pressure air circulation is replaced with a positive-pressure air circulation, which makes it even more difficult to conduct an early warning for spontaneous combustion in the mine goafs. Moreover, this may also cause fresh air to enter the adjacent goafs or the high-fire-hazard-risk area, the first of which may lead to spontaneous combustion, whereas the second may result in the expansion of the combustion range. Hence, the Coal Production Technology and Equipment Policy Orientation, jointly issued by four ministries, including the National Development and Reform Commission, specifies the openarea pressure equalization technology as a restricted application technology and stipulates the prohibition of carrying out pressure equalization in working surfaces with high gas content [21].

In this paper, the development pattern of fractures in the overlying strata formed by close-distance coal seam mining was numerically simulated based on the horizontal stress "normalization" technique. Meanwhile, the air-leak passageways and the corresponding leakage scope were tested using the $\mathrm{SF}_{6}$ tracer gas analysis, thereby not only providing a theoretic basis for harmful toxic gas intrusion disasters in the fire-hazard-risk area in small coal pits but also guiding the prevention and control of gas intrusion disasters. By drilling a hole through the construction surface, inorganic foaming and curing filling materials can be poured into the mine goaf to block the principal air-leak passageways. When these are conducted in conjunction with removal projects for the fire-hazard-risk area in a small coal pit, the occurrence of 
harmful toxic gas intrusion disasters in the process of closedistance coal seam mining can be effectively prevented and controlled, while the safety of mining activities on the working surfaces can also be simultaneously ensured.

\section{Project Overview}

The primary coal seam 31\# in the Shigetai Coal Mine of Shendong mining area has a burial depth that ranges from $109 \mathrm{~m}$ to $132 \mathrm{~m}$, with a coal seam thickness of $3.9 \mathrm{~m}$ and a dip angle that ranges from $1^{\circ}$ to $3^{\circ}$, belonging to Class I spontaneous combustion coal seam. There were coal seam 22\#, coal seam 12\#, and upper coal seam 12\# on the overlying strata of coal seam $31 \#$, of which coal seam $22 \#$ has been completely exploited and now has a coal seam thickness of $4.8 \mathrm{~m}$, while coal seam 12\# and upper coal seam 12\# have not been mined. The distance between coal seam 31\# and coal seam $22 \#$ is about $38.2 \mathrm{~m}$, and the distance between coal seam 22\# and coal seam 12\# is about $31.2 \mathrm{~m}$; hence, they can be categorized as a close-distance coal seam group. Their structure is shown in Figure 1.

There are 24 small pits around the Shigetai Coal Mine, all of which are mainly distributed in the first and second panels. Most of the small pits have been closed down by 2011. The surrounding small pits are adjacent to or overlapping with larger coal mine fields. Severe occurrences of illegal mining are prevalent in the small pit, some of which have even been mined over their predetermined boundaries into the territories of the larger mine shafts. While the methods of mining selected are unclear, the signs of roomand-pillar-type mining are the most predominantly found, and the locations of the small pit passageways are unknown [22]. Due to the large numbers of disorderly mined small pits, the locations of small pit goafs are erratically scattered, most of which are interpenetrated. Huge amounts of residual coals can also be found in the goafs, where the ventilation is poor, making it easy for oxidative spontaneous combustion to happen. The environment where surface fissures and collapses are connected to abandon wellheads and passageways, forming cyclic exchanges between the underground high-temperature air flow and surface lowtemperature air flow after contacting with the surface atmosphere, provides the oxygen supply required for the development of the fire-hazard-risk area in small coal pits. If it is not blocked timely, it may lead to the spread of coal fires and ignition of the surrounding coal seams, ultimately causing the massive aerial formation of fire-hazard-risk area in small coal pits.

High-concentration gases resulting from the fire could be found in primary coal seam 12\# and coal seam 22 \# of the 7 small pits to the south of the third panel of the Shigetai Coal Mine. Its $\mathrm{CO}$ and $\mathrm{C}_{2} \mathrm{H}_{4}$ volume fractions reach as high as $0.8129 \%$ and $0.0125 \%$, respectively, indicating that the firehazard-risk area in small coal pits have been formed. $20 \mathrm{~m}$ to $30 \mathrm{~m}$ security coal pillars between the small pits and large mine fields are retained, but cross-boundary mining can also be found in small pits such as the Tangjiangqu mMine, Qianqu Mine, Yemaowan Mine, and Tangjiangqu 2nd Mine. Moreover, both the cross-boundary positions and the degrees are unknown. Security coal pillars are easily deformed and broken under the action of long-term underground pressure, forming a system of interconnecting air-leak passageways between the small pit and the goaf of larger mines.

Multiple technical means, such as blocking the wellheads in the small pit, nitrogen injection, and partial stripping have been carried out successively to deal with the fire-hazard-risk area in small coal pit. However, the high-fire-hazard-risk area has not been effectively treated. When the 31201 working surface of the Shigetai Coal Mine was $75 \mathrm{~m}$ away from the cutting hole position, the $\mathrm{CO}$ volume fraction of the return air corner increased abruptly from $0.0021 \%$ to $0.0128 \%$ and remained at $0.01 \%$ to $0.0188 \%$. The $\mathrm{CO}$ volume fraction of the goaf increased from $0.006 \%$ to $0.02 \%$ and remained at $0.0134 \%$ to $0.0244 \%$. Moreover, the CO volume fraction of the overlying coal seam 22 \# goaf increased from $0.01 \%$ to $0.062 \%$ and remained at $0.05 \%$ to $0.112 \%$. As the $\mathrm{CO}$ volume fractions have been abruptly increased at each monitoring point with a noncontinuous growth trend, and no other fire gases such as $\mathrm{C}_{2} \mathrm{H}_{4}$ and $\mathrm{C}_{2} \mathrm{H}_{2}$ were detected, the possibility of spontaneous combustion in the goaf was ruled out. This was deemed as the result of harmful toxic gases in the small pit flowing to a variety of monitoring points through fractures under the action of negative ventilation pressure.

\section{Pattern of Fracture Development}

3.1. Selection of Macroparameters. In a previous study [23], an empirical equation for macroscopic parameters of the material was established with $\mathrm{PFC}^{2 \mathrm{D}}$. A histogram with three drilling holes was formulated in line with the second panel of coal seam $31 \#$ in the Shigetai Coal Mine, as shown in Figure 2.

3.2. Model Establishment. According to the histogram of the Shigetai Coal Mine geological synthesis in Figure 3, the model shown in Figure 3 was established using the central symmetry model using FLAC 2D 5.0, with the length and height set to $160 \mathrm{~m}$ and $135 \mathrm{~m}$, respectively.

The measured ground stress in the Shigetai Coal Mine is shown in Table 1.

Due to the unique industrial and mining conditions in the Shendong mining area, it is difficult to analyze the roof damage evolution process and collapse failure mechanism of the Shendong mining area using the traditional mining area theory. Based on this, by referring to the horizontal stress "normalization technology" established by Jan (2016) [24], normalization was conducted on the horizontal stress in line with the elastic property of the overlying strata as follows:

$$
\sigma_{\mathrm{NL}}=\frac{E_{N}}{E_{M}\left[\left(\sigma_{\mathrm{ML}}-\sigma_{V} \vartheta\right) /(1-\vartheta)\right]}+\frac{\sigma_{V} \vartheta}{(1-\vartheta)},
$$

where $\sigma_{\mathrm{NL}}$ is the normalised horizontal stress, in MPa; $\sigma_{\mathrm{ML}}$ is the horizontal stress of the measurement layer, in MPa; $\sigma_{V}$ is the vertical stress of the measurement layer, in MPa; $E_{N}$ is the normalised Young's modulus, in $\mathrm{MPa} ; E_{M}$ is Young's modulus of the measurement layer, in $\mathrm{MPa}$; and $v$ is Poisson's ratio. 


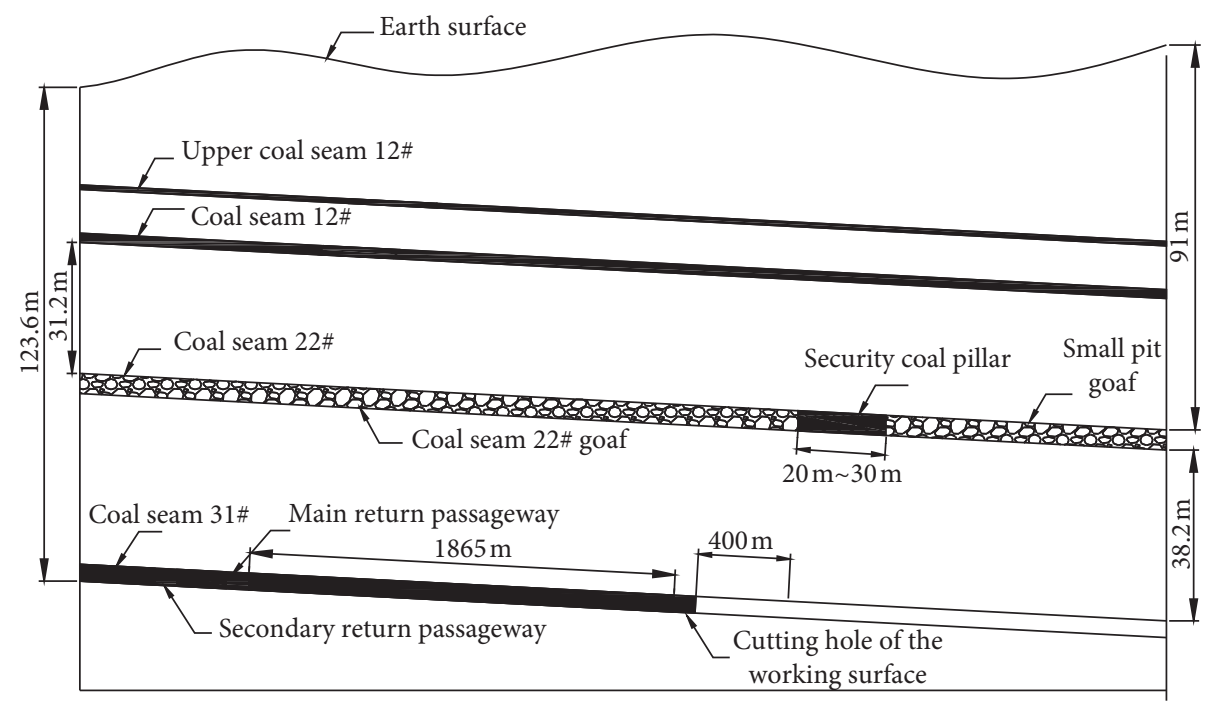

FIGURE 1: Relationship between coal seam 31\# and the overlying coal seam.

\begin{tabular}{|c|c|c|c|c|c|c|c|c|c|}
\hline $\begin{array}{l}\text { Seam } \\
\text { no }\end{array}$ & Lithology & $\begin{array}{l}\text { Seam } \\
\text { thickness } \\
(\mathrm{m})\end{array}$ & $\begin{array}{l}\text { Burial } \\
\text { depth } \\
\text { (m) }\end{array}$ & Columnar & $\begin{array}{l}\text { Poisson's } \\
\text { ratio }\end{array}$ & $\begin{array}{c}\text { Elastic } \\
\text { modulus }\end{array}$ & $\begin{array}{c}\text { Tesnsile } \\
\text { strength } \\
(\mathrm{MPa})\end{array}$ & $\begin{array}{c}\text { Cohesion } \\
(\mathrm{MPa})\end{array}$ & $\begin{array}{l}\text { Internal } \\
\text { friction } \\
\text { angle }\left(^{\circ}\right)\end{array}$ \\
\hline 27 & Aeolian sand & 5.14 & 5.14 & \multirow{4}{*}{ 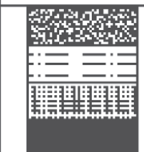 } & & & & & \\
\hline 26 & Sandy mudstone & 19.15 & 24.29 & & 0.17 & 7.4 & 1.6 & 7.6 & 38.8 \\
\hline 25 & Medium sandstone & 9.62 & 33.91 & & 0.18 & 15.4 & 2.58 & 4.35 & 35.3 \\
\hline 24 & Coal seam 11\# & 0.6 & 34.51 & & 0.27 & 6.9 & 1.33 & 2.42 & 42.6 \\
\hline 23 & Sandy mudstone & 0.4 & 34.91 & \multirow{4}{*}{ 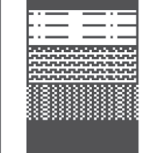 } & 0.17 & 7.4 & 1.6 & 7.6 & 38.8 \\
\hline 22 & Fine sandstone & 7.38 & 42.29 & & 0.14 & 17.4 & 3.06 & 5.77 & 38.8 \\
\hline 21 & Siltstone & 0.3 & 42.59 & & 0.23 & 9.7 & 4.66 & 11.5 & 36 \\
\hline 20 & Upper coal seam 12\# & 1.52 & 44.11 & & 0.27 & 6.9 & 1.33 & 2.42 & 42.6 \\
\hline 19 & Fine sandstone & 2.1 & 46.21 & \multirow{4}{*}{ 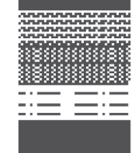 } & 0.14 & 17.4 & 3.06 & 5.77 & 38.8 \\
\hline 18 & Siltstone & 7.43 & 53.64 & & 0.23 & 9.7 & 4.66 & 11.05 & 36 \\
\hline 17 & Sandy mudstone & 1.59 & 55.23 & & 0.17 & 7.4 & 1.6 & 7.6 & 38.8 \\
\hline 16 & Coal seam 12\# & 2.26 & 57.49 & & 0.27 & 6.9 & 1.33 & 2.42 & 42.6 \\
\hline 15 & Sandy mudstone & 0.9 & 58.39 & \multirow{7}{*}{ 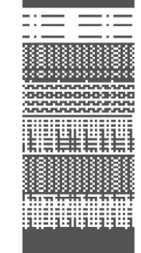 } & 0.17 & 7.4 & 1.6 & 7.6 & 38.8 \\
\hline 14 & Siltstone & 4.92 & 63.31 & & 0.23 & 9.7 & 4.66 & 11.05 & 36 \\
\hline 13 & Fine sandstone & 7.49 & 70.8 & & 0.14 & 17.4 & 3.06 & 5.77 & 38.8 \\
\hline 12 & Medium sandstone & 2.2 & 73 & & 0.18 & 15.4 & 2.58 & 4.35 & 35.3 \\
\hline 11 & Siltstone & 4.04 & 77.04 & & 0.23 & 9.7 & 4.66 & 11.05 & 36 \\
\hline 10 & Medium sandstone & 2.8 & 79.84 & & 0.18 & 15.4 & 2.58 & 4.35 & 35.3 \\
\hline 9 & Upper coal seam 22\# & 3.71 & 83.55 & & 0.27 & 6.9 & 1.33 & 2.42 & 42.6 \\
\hline 8 & Mudstone & 1.43 & 84.98 & \multirow{2}{*}{ 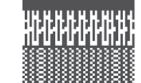 } & 0.15 & 7.2 & 1.36 & 6.32 & 39.4 \\
\hline 7 & Siltstone & 15.43 & 100.41 & & 0.23 & 9.7 & 4.66 & 11.05 & 36 \\
\hline 6 & Fine sandstone & 6.94 & 107.35 & \multirow[b]{3}{*}{ 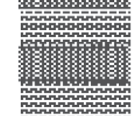 } & 0.14 & 17.4 & 3.06 & 5.77 & 38.8 \\
\hline 5 & Siltstone & 5.33 & 112.68 & & 0.23 & 9.7 & 4.66 & 11.05 & 36 \\
\hline 4 & Fine sandstone & 6.48 & 119.16 & & 0.14 & 17.4 & 3.06 & 5.77 & 38.8 \\
\hline 3 & Siltstone & 1.05 & 120.21 & \multirow[t]{3}{*}{ IIII } & 0.23 & 9.7 & 4.66 & 11.05 & 36 \\
\hline 2 & Upper coal seam 31\# & 3.8 & 124.01 & & 0.27 & 6.9 & 1.33 & 2.42 & 42.6 \\
\hline 1 & Siltstone & 2.8 & 126.81 & & 0.23 & 9.7 & 4.66 & 11.05 & 36 \\
\hline
\end{tabular}

FIgURE 2: Macrophysical and mechanical properties of the coal seam and strata.

The top of the model was the surface, which was set as a free boundary, while the bottom was set as a fixed constrained boundary. A bonded face was set between the fracture zone and the caving zone inside the model, and a structural surface was set between the fractured zone and the caving zone. The cutting hole and its overlying strata were set as the vertical structural surface. Moreover, horizontal loads were applied horizontally in the model based on the measured stress and the calculated equivalent stress.

3.3. Result Analysis. When the working surface of coal seam 31\# in the Shigetai Coal Mine has been mined to a position $92 \mathrm{~m}$ from the cutting hole, the displacement vector and 


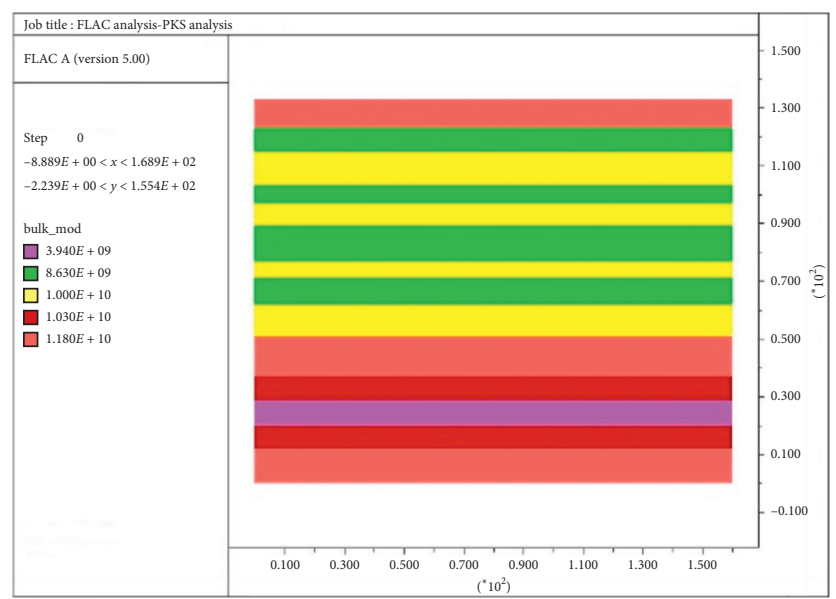

FIgURE 3: Numerical simulation model.

TABLE 1: Actual measured ground stress.

\begin{tabular}{lcccc}
\hline Measured location & Stress category & Principal stress value (MPa) & Azimuth $\left(^{\circ}\right)$ & Dip angle $\left(^{\circ}\right)$ \\
\hline \multirow{3}{*}{31201 air-return laneway } & Maximum principal stress $\sigma_{1}$ & 6.57 & 264.7 & 2.9 \\
& Intermediate principal stress $\sigma_{2}$ & 5.76 & 37.0 & 85.7 \\
& Minimum principal stress $\sigma_{3}$ & 5.15 & 174.5 & 3.1 \\
\hline
\end{tabular}

plastic deformation of the overburden strata can be shown in Figure 4 . The distance and strength analysis results of the first roof weighting and periodic weighting are shown in Figure 5. The process of fracture development in the overlying rock layer is shown in Figure 6.

The immediate roof was caved immediately after the mining of the working surface. The caving zone ranges from $73 \mathrm{~m}$ to $94 \mathrm{~m}$ in height, and the fractured zone developed all the way to the surface. Subsequent roof weighting occurred thrice at the weighting interval of about $10 \mathrm{~m}$ after the roof weighting position reached $67 \mathrm{~m}$ away from the cutting hole position. The maximum strength was obtained in the first weighting. Apparent stratification could be witnessed in the early stage of fracture formation. Gradually, shear fractures were formed around the coal pillar with the development of the working surface, whereas stratified fractures away from the working surface were compacted. Consequently, shear fractures have transformed into the major air-leak passageways.

According to [25], the coalfield high-fire-hazard-risk area comprises three basic types (structural fractures, mining collapse fractures, and combustion fractures) and five composite types. These fractures connected oxygen with underground coal seams or the residual coal in goafs, forming a primary passageway consisting of air-leaked oxygen supply, heat dissipation, smoke exhaust, and venting circulation. Meanwhile, a point $\longrightarrow$ line $\longrightarrow$ area expansion evolution of the coalfield fire also took place. Although the $20 \mathrm{~m}$ to $30 \mathrm{~m}$ security coal pillars are retained between the fire-hazard-risk area in small coal pit and the Shigetai Coal Mine, they still have the abovementioned fractures, and some of which have suffered from the cross-boundary mining. Harmful toxic gases in the fire-hazard-risk area in small coal pits inevitably came into contact with the overlying goaf of coal seam 31\#. Harmful toxic gases then permeate into the working surface through fractures on the security coal pillars and shear fractures of coal seam 31\#'s overlying strata under the joint effect of negative air circulation and atmospheric pressure. The first weighting of the working surface occurred $67 \mathrm{~m}$ away from the cutting hole. $\mathrm{CO}$ gas anomaly was detected at a $75 \mathrm{~m}$ mark along the progression of the working surface. The consistent time frames proved the validity of the model.

\section{The Search for Air-Leak Passageways}

$\mathrm{SF}_{6}$ tracer gas analysis was employed to determine the interconnections and influencing range of the fire-hazard-risk area in small coal pit and the working surface, so as to verify the presence of air-leak passageways.

4.1. Determination of Air-Leaking Source. Concealed combustion sources in parts of the small pits in the south of the Shigetai Mine Coal were detected using the instantaneous (differential) radon measurement method [26]. Collected gases were tested directly with the alpha particle detector in the RAD7 professional electronic radon meter. Meanwhile, radon measurement data were also processed, as shown in Figure 7 .

The temperature anomaly area was about $5000 \mathrm{~m}^{2}$ and was located to the east of the former Qianqiu coal mine office area, belonging to the joint airway overlying area \#24 of the 31206 main and auxiliary transport passageway in the Shigetai Coal Mine. The location was selected as the air-leak source or the area releasing $\mathrm{SF}_{6}$. 


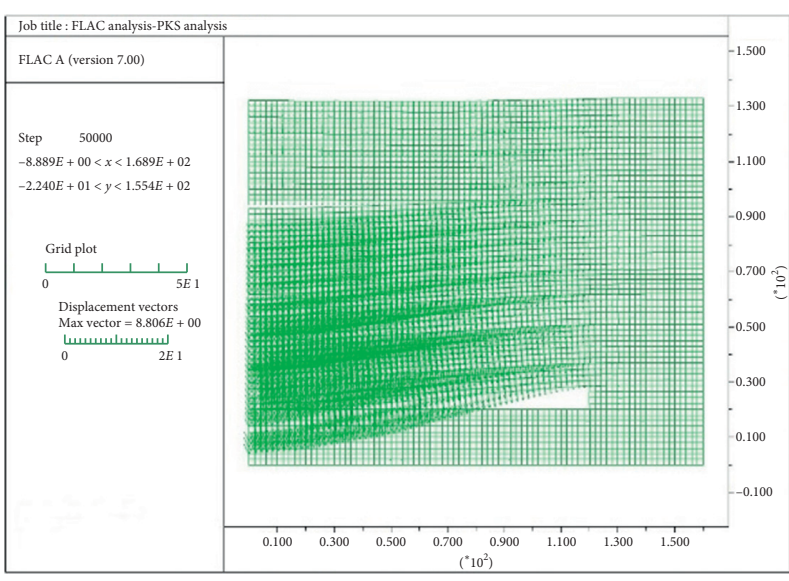

(a)

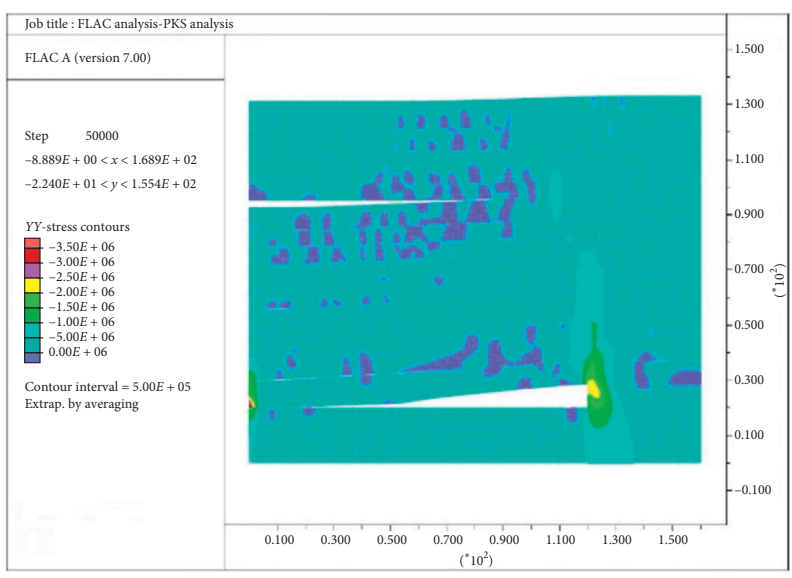

(b)

FIgURE 4: (a) Displacement vector and (b) plastic deformation of overlying strata.

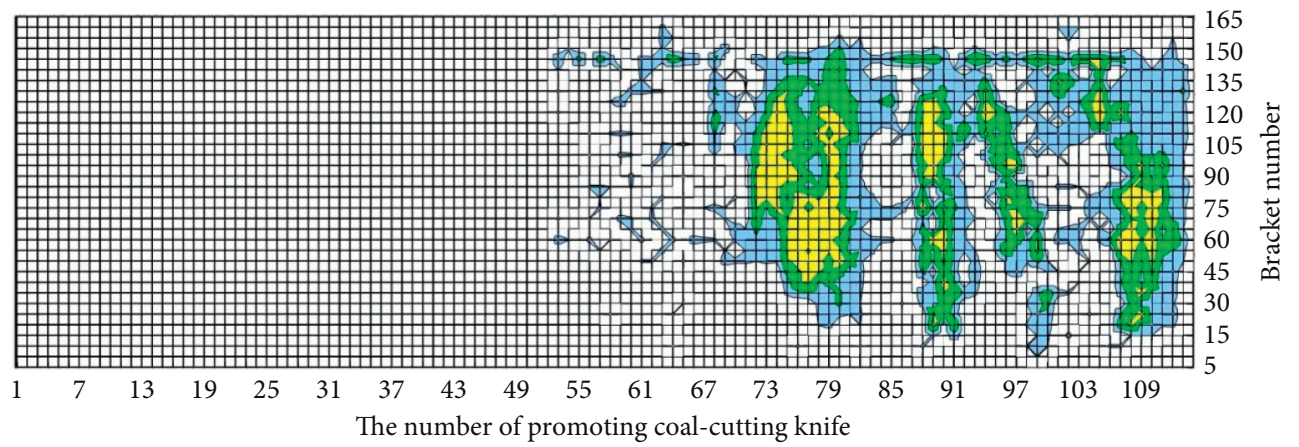

FIgURE 5: The distance and strength of first and periodic roof weighting.
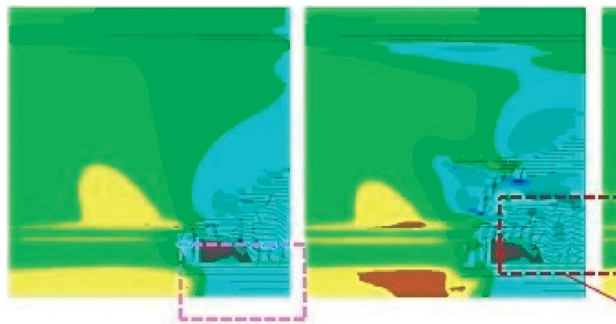

Layered fracture

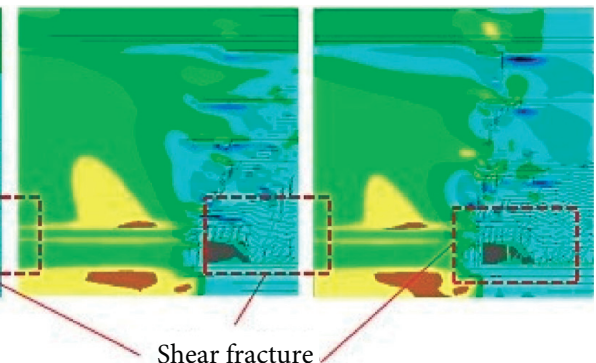

FIgURE 6: Fracture development in the overlying strata.

4.2. Determination of Air Leakage. $\mathrm{SF}_{6}$ gas with $99.99 \%$ concentration was released all in once at the air-leak source using instantaneous release with the release rate of $2 \mathrm{~L} / \mathrm{min}$ and the continuous release time of 2 hours. The 31201 return air corner, 31201 return air roadway joint roadway $26 \#$ closed observation hole, 31201 auxiliary transport roadway joint airway 34\# closed observation hole, and 31202 cutting hole $2 \#$ and 5\# drawing off water holes in the shunting chamber (detecting the goaf of overlying coal mine 22\#) were selected as receiving locations. Gas samples were collected every $10 \mathrm{~min}$ to $20 \mathrm{~min}$ at the underground reception site, while the testing time was decided according to the specific situation. The release time of air-leaking $\mathrm{SF}_{6}$ was 12:00 at the air-leakage measurement. The underground detection lasted for 3 hours. Collected gas samples were analyzed with a gas chromatograph to determine whether the sample contained $\mathrm{SF}_{6}$ gas. The test results are shown in Table 2.

According to the measurement results, air-leak passageways can be found among the fire-hazard-risk areas in a small coal pit, coal seam 22\# goaf and coal seam 31 \# goaf. The air-leaking route stretched from the fire-hazard-risk area in 


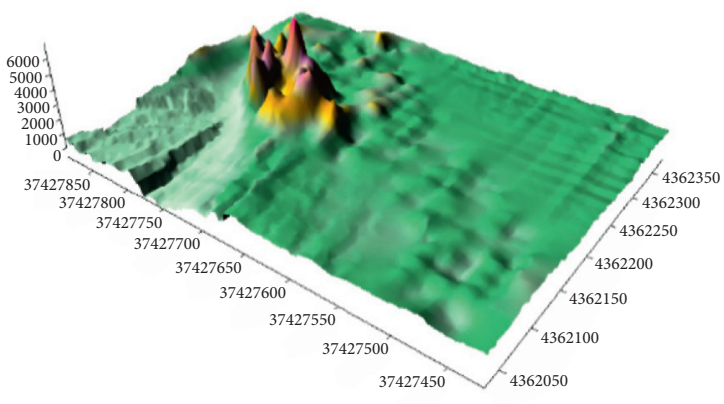

(a)

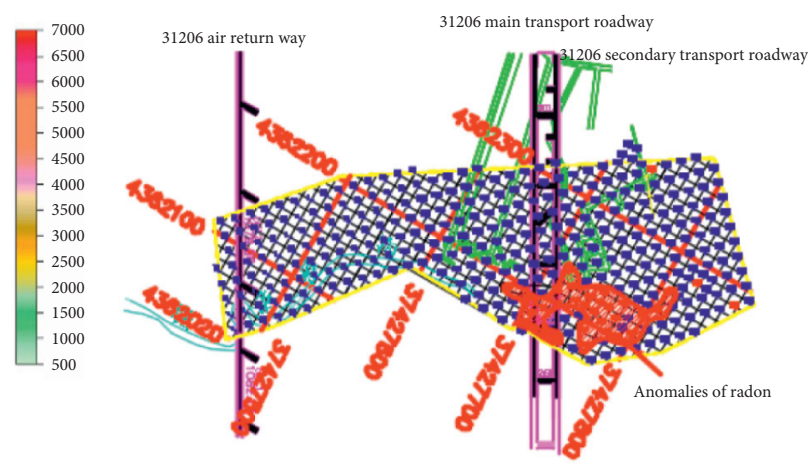

(b)

Figure 7: Temperature anomaly. (a) Radon surface concentration. (b) Anomalies of radon.

TABLE 2: $\mathrm{SF}_{6}$ gas sample analysis results.

\begin{tabular}{lcc}
\hline Sampling location & Sampling time & Volume content $\left(\times 10^{-6}\right)$ \\
\hline \multirow{2}{*}{31202 cutting hole 2\# drawing off water hole } & $12: 30$ & 1.2129 \\
& $12: 50$ & 1.1048 \\
\hline \multirow{2}{*}{31202 cutting hole 5\# drawing off water hole } & $12: 20$ & 1.0376 \\
& $12: 40$ & 1.3867 \\
\multirow{2}{*}{31201 return air roadway joint roadway 26\# closed observation hole } & $12: 50$ & 2.8301 \\
\hline \multirow{2}{*}{31201 auxiliary transport roadway joint airway 34\# closed observation hole } & $13: 00$ & 1.6324 \\
\hline \multirow{2}{*}{31201 return air corner } & $13: 55$ & 1.2351 \\
& $13: 15$ & 1.0235 \\
\hline \multirow{2}{*}{31201 return air flow } & $13: 35$ & 0.9562 \\
\hline
\end{tabular}

the small coal pit to the goafs of coal seam $22 \#$ and coal seam $31 \#$, as shown in Figure 8.

\section{Partitioning the High-Fire-Hazard-Risk Area with Inorganic Curing Materials}

By analyzing the development pattern of fractures in the overlying strata on the working surface, it can be seen that fractures generated after the cessation of the working surface provide passageways for the intrusion of harmful toxic gases, which will severely threaten the safe mining of the working surface. The local government has led a local stripping fire extinguishing project for the small pit in the south of the Shigetai Coal Mine since October 2014, which is composed of Liushipan open-air stripping and Tangjiangqu 2nd Mine open-pit stripping. Specifically, the Liushipan Comprehensive Treatment Project Team stripped the Liushipan Coal Mine, Beidaqu Mine, and Shenfu Tanyaoqu Mine in the south of the Tangjiangqu ditch for fire distinguishing. And the Tangjiangqu 2nd Mine Comprehensive Management Project Team stripped the Tangjiangqu 2nd Mine in the northeast of the Tangjiangqu ditch for fire distinguishing. But the Yemaowan Mine, Tangjiangqu Mine, and Qianqu Mine in the north of the Tangjiangqu ditch (near the second panel of 31\# coal seam) were not included in the stripping treatment. A technique of filling inorganic curing materials into the drilling holes of the construction surface for fire isolation has been proposed against the area without stripping.

5.1. Inorganic Foaming and Curing Materials. Materials used for fire isolation should effectively block air-leak passageways with a high expansion ratio and certain strength. Based on this, cementing materials dominated by aluminosilicate were selected as main raw materials in conjunction with the accelerator and composite reinforcing agent for improving the setting speed and initial setting strength. Furthermore, the composite foaming agent was employed to increase its expansion ratio, satisfying the requirements of filling and isolating high-fire-hazard-risk areas [27].

52.5 sulfoaluminate cement was selected as main material of the cementing material. Besides, $\mathrm{Ca}(\mathrm{OH})_{2}$ exciter and accelerator must be added due to insufficient active alkali ions. The excitation of $\mathrm{Ca}(\mathrm{OH})_{2}$ on the activity of cementing materials provided not only $(\mathrm{OH})^{-}$that breaks the bond of $\mathrm{Si}-\mathrm{O}$ and $\mathrm{Al}-\mathrm{O}$ but also $\mathrm{Ca}^{2+}$ required for hydrating the cementing material to form a hard cementing material.

The reinforcing agent was mainly composed of sulfate, and $\mathrm{Aft}$, or ettringite generated by $\mathrm{SO}_{4}{ }^{2-}$, and $\mathrm{Al}_{2} \mathrm{O}_{3}$ dissolved in the liquid phase under the action of $\mathrm{Ca}^{2+}$ was the 


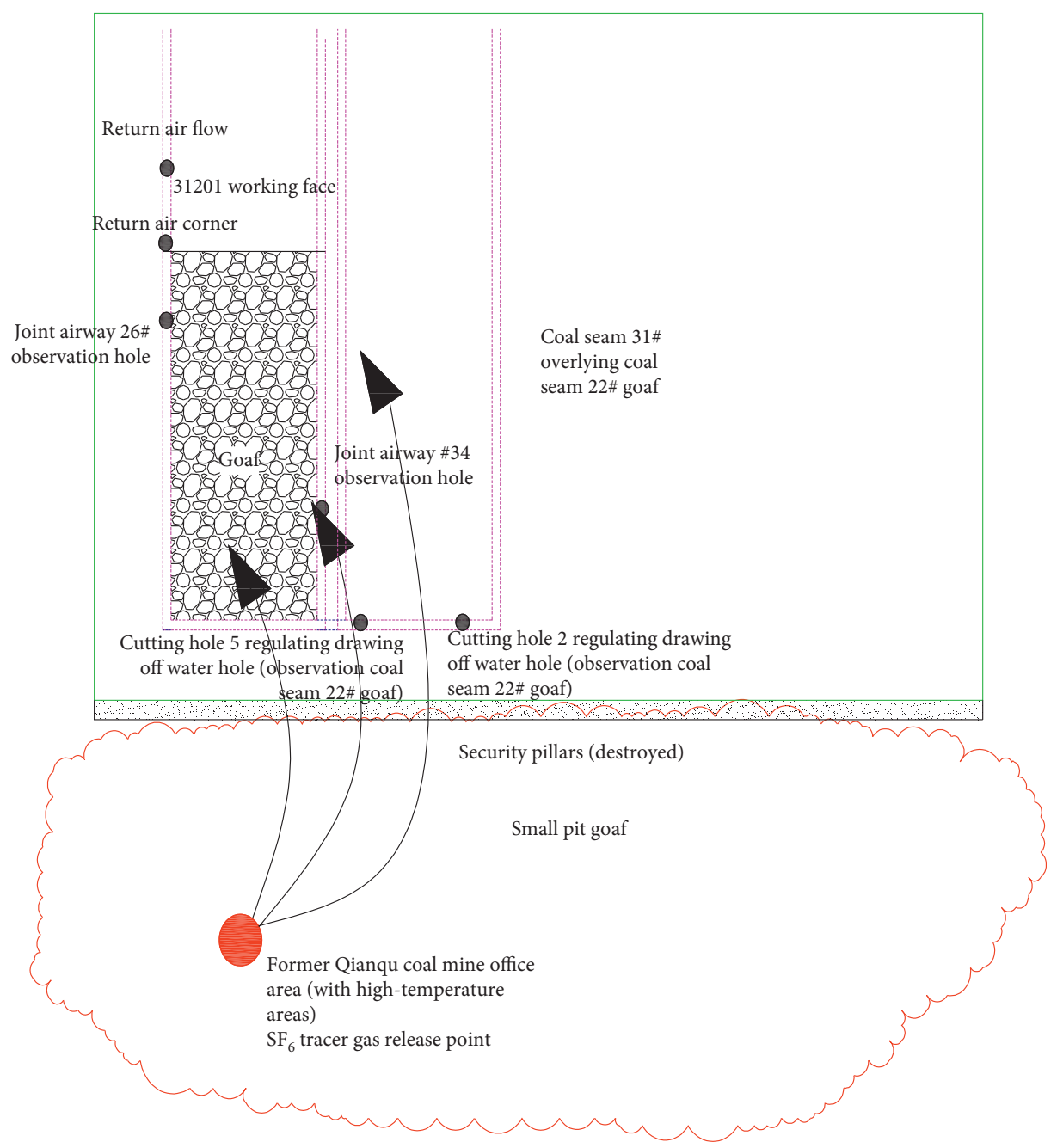

FIGURE 8: Detection of air-leaking route.

excitation of activity of the cementing material. $\mathrm{Na}_{2} \mathrm{SO}_{4}$ that is more soluble in water was selected as sulfate, which can form highly dispersed $\mathrm{CaSO}_{4}$ upon the reaction with $\mathrm{Ca}$ $(\mathrm{OH})_{2}$, enhancing the alkalinity of the material. Tests proved that scum could be caused when the added amount of $\mathrm{Na}_{2} \mathrm{SO}_{4}$ exceeded 3\%, and microcracks could be detected inside the test block, leading to the decline in strength in the later period [28]. $2 \%$ of $\mathrm{Na}_{2} \mathrm{SO}_{4}$ was added in the material.

High-efficiency quick-setting agent was selected as the initial and final setting regulator of the material, so that the initial and final setting time and compressive strength of the material could be more stable. After adding different amounts of quick-setting agent, the setting time of the cured material can be adjusted from 2 minutes to 6 hours. Besides, primary liquid could maintain a high strength after foaming. $3 \%$ of accelerator was added in the material.
A variety of surfactants and foam stabilizing agents were selected and mixed as the foaming agent stock can produce foaming agent mixtures upon the mixture of water at a certain ratio. And fine foams can be formed upon mixing with the compressed air.

With cementing materials as the base materials, reinforcing agent, water-reducing agent, and quick-setting agent were added in proportion to form a powdery curing material, forming slurry liquid with the mixture of a small amount of water. Meanwhile, foams were obtained using the foaming agent. The slurry liquid was mixed with foams to form the foaming liquid and deliver to the designated site through pumps. Inorganic curing filling materials were obtained. Basic properties of the material are shown in Table 3.

The pore structure of the inorganic cured material was observed at a magnification of 60 times under an optical microscope, as shown in Figure 9. 
TABLE 3: Test results of properties of inorganic cured materials.

\begin{tabular}{lcc}
\hline Density $\left(\mathrm{kg} / \mathrm{m}^{3}\right)$ & Compressive strength $(\mathrm{MPa})$ & Air tightness $\left(\mathrm{m}^{3} /\left(\mathrm{m}^{2} / \mathrm{min}^{2}\right)\right.$ \\
\hline 250 & 1.8 & $0.85 \times 10^{-6}$ \\
\hline
\end{tabular}

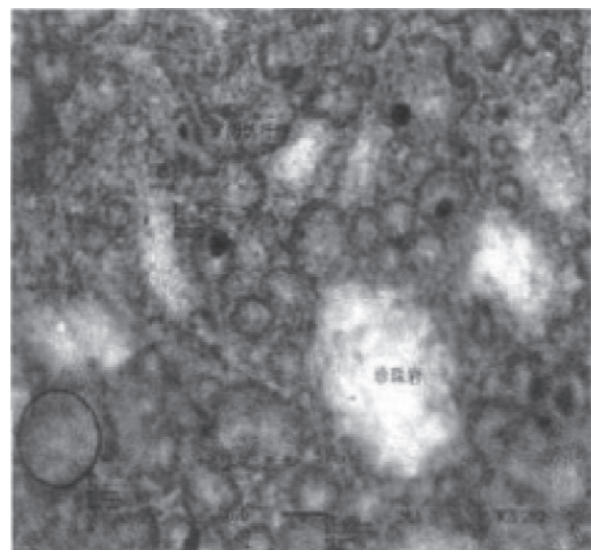

(a)

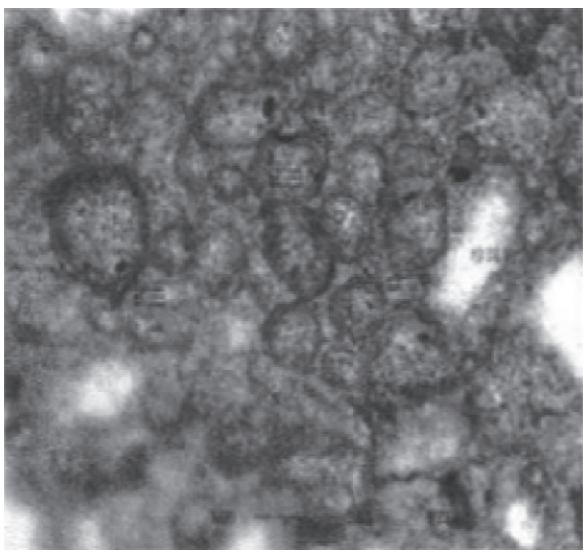

(b)

FIGURE 9: Material hole structure.

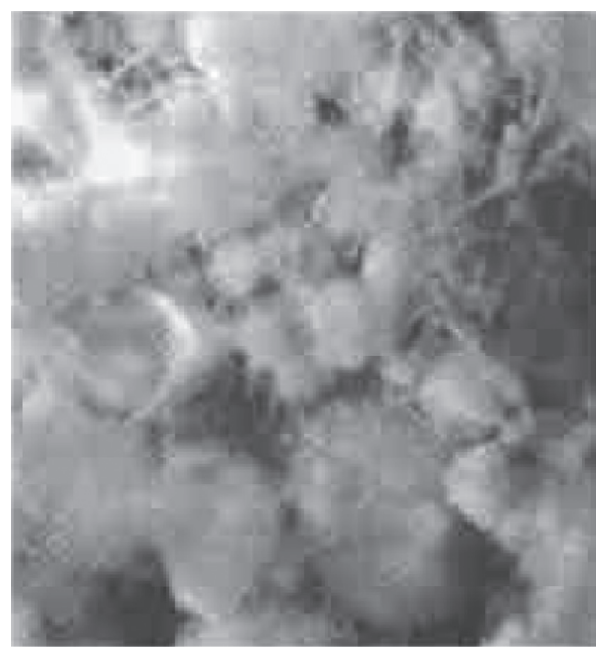

(a)

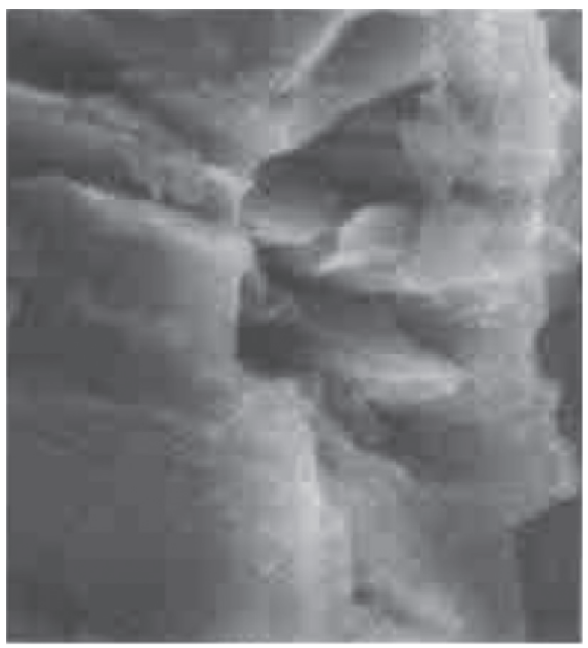

(b)

Figure 10: Material SEM photo. (a) Curing period: 3 days. (b) Curing period 28 days.

Pores inside the material are evenly distributed at the pore diameter below $1 \mathrm{~mm}$. Most of which are closed circular holes, exerting a good effect of blocking air leakage.

Internal structures of inorganic curing materials in different curing periods were observed with the scanning electron microscope. SEM photos are shown in Figure 10.

During material molding, a large amount of ettringite crystals were formed and connected into pieces or even covered the whole test sample with the extended curing time. In this way, the compressive strength of the material was increased.
5.2. Surface Drilling Design. Regarding the area that is not stripping in the small pit, 22\# coal goaf construction surface was drilled along the security coal pillars between the small pit and the 22\# coal goaf. The final position of the drilling hole was located at $3 \mathrm{~m}$ in the north of the security coal pillar. Inorganic curing filling materials were poured through the surface drilling hole to build an isolation zone, so as to remove the influence of harmful toxic gas in the small pit goaf on the safe stopping of the 31\# coal second panel.

The first ground drilling hole (GL1) was arranged at $30 \mathrm{~m}$ away from the 220403 working surface along the roadway, 


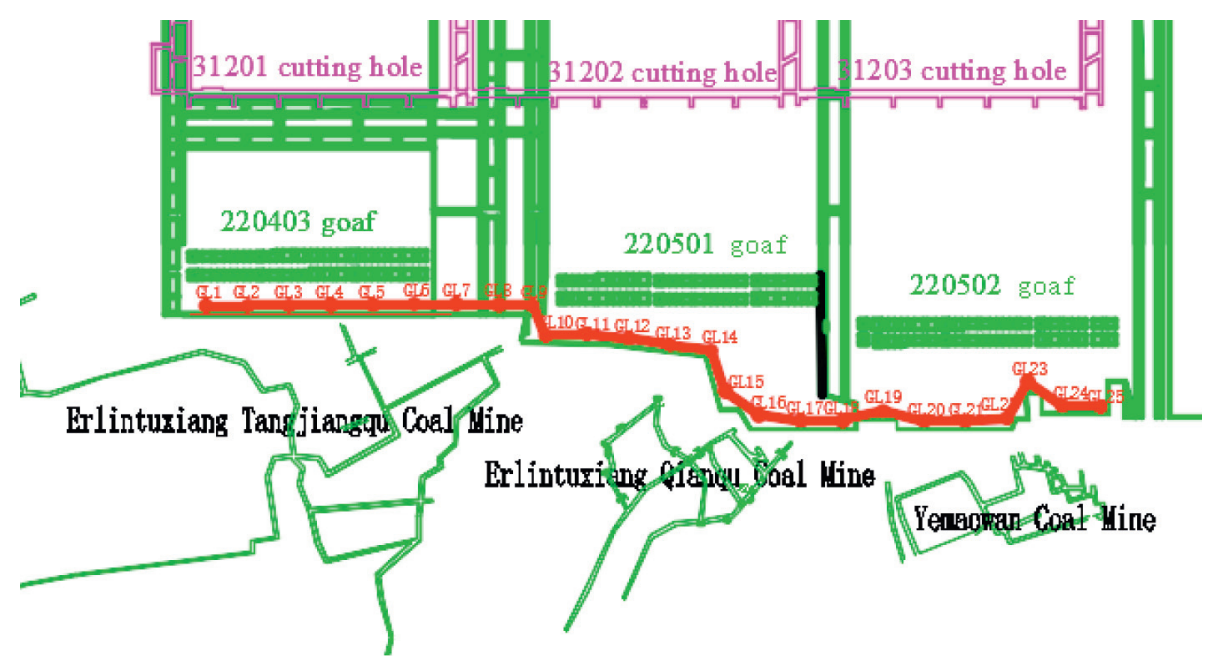

Figure 11: Construction of the isolation zone.

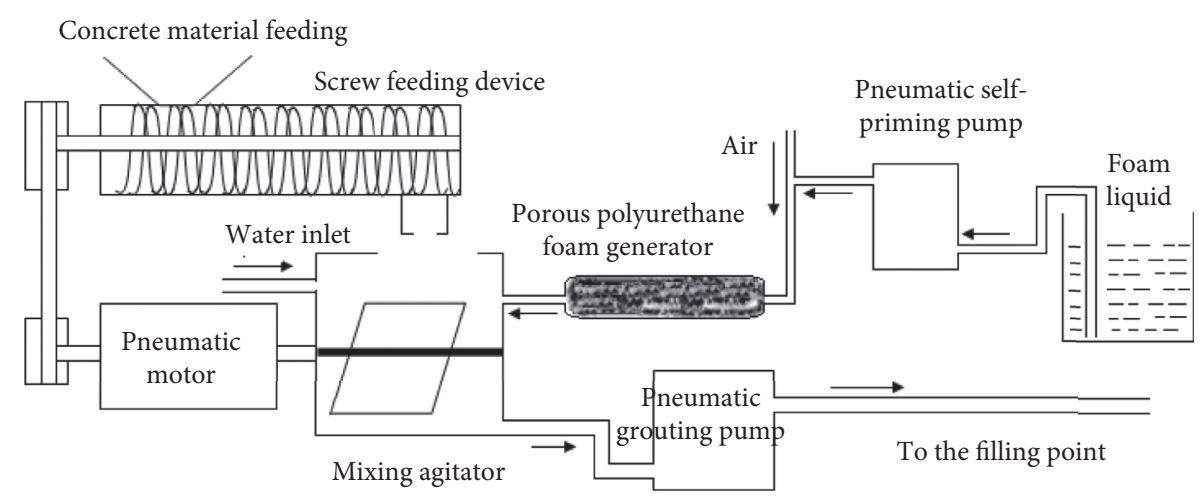

FIGURE 12: Filling and pouring process of inorganic foaming and curing.

and one ground drilling hole was constructed every $50 \mathrm{~m}$ along the direction of the security coal pillar. The entire isolation zone is covered from 220403 goaf to 220502 goaf, covering 31\# coal seam 31201, 31202, and 31203 working surfaces. With $1100 \mathrm{~m}$ in total, a total of 25 grouting holes were designed, as shown in Figure 11.

5.3. Pouring Technique and Plugging Capacity. The compressed air was used as power to pour inorganic solidified filling materials with the pneumatic equipment. Inorganic curing filler materials were added to the feed port, and water was added to the mixer driven by the pneumatic air motor. The ratio of water volume and inorganic curing filler is $1: 1$ to $1: 2$. Besides, the foaming agent and water are mixed as foaming liquid at $1: 30$, which forms foams upon the contact of the pneumatic self-priming pump and the compressed air. And fine foams were generated through the porous polyurethane foam generator. After that, fine foams and inorganic curing fillers were transported to drilling holes in the ground, forming foaming fillers in the goaf. Ultimately, an isolation zone was constructed, as shown in Figure 12.

When the isolation zone was constructed, the $\mathrm{SF}_{6}$ tracer gas analysis technology was utilized once more to detect air leakage. The $\mathrm{SF}_{6}$ release location remained the abovementioned temperature anomaly area, and the receiving location was the return air corner of the working surface of $31 \#$ coal second panel, 31\# coal goaf, and overlying 22\# coal goaf. $\mathrm{No} \mathrm{SF}_{6}$ gas was detected from the collected gas samples, indicating that the 22 \# coal goaf was well isolated from the small pit goaf.

Under the combined effect of the stripping and isolation of the fire-hazard-risk area in a small coal pit, the remaining working surfaces (31202 to 31205 working surfaces) of the 31\# coal 2nd panel of the Shigetai Coal Mine have not been affected by the harmful toxic gas in the fire-hazard-risk area in a small coal pit during the mining process, safeguarding the safe cessation of the working surface.

\section{Conclusions}

(1) The movement rule of overlying strata and the development process of fissures are simulated numerically based on the horizontal stress "normalisation" technology. The immediate roof is caved immediately after the underlying coal seam is mined. The caving zone ranged from $73 \mathrm{~m}$ to $94 \mathrm{~m}$ in height, and the fractured zone is developed through 
the surface. Apparent stratification can be witnessed in the early stage of formation. Gradually, shear fractures are formed, whereas stratified fractures are compacted. As a result, shear fractures become major air-leak passageways. The roof weighting position is $67 \mathrm{~m}$ away from the cutting hole position, which is nearly consistent with the time node of gas intrusion into the working surface in the fire zone.

(2) $\mathrm{SF}_{6}$ tracer gas analysis technology is used to further verify and judge the air leakage channel and the affected range. Air-leak passageways and their influencing ranges were verified with the $\mathrm{SF}_{6}$ tracer analysis. The firehazard-risk area in small coal pit detected by the radon measurement technique is regarded as the release point. Meanwhile, the return air corner of the working surface, return air flow, goaf, and overlaying coal seam goaf are considered as receiving points. $\mathrm{SF}_{6}$ gases are received in all receiving points. Based on the analysis of the movement pattern of the overlying strata, harmful toxic gases can penetrate into the working surface through fractures on the security coal pillars and shear fractures of the overlying strata on the working surface under the joint effect of negative air circulation and atmospheric pressure.

(3) An inorganic foaming and curing filling material that can effectively block the air-leak passageway and construct the isolation zone is introduced. The construction ground is drilled in the area, and inorganic foaming and curing filling materials are poured to the mine goaf for constructing an isolation belt to block principal air-leak passageways, which can effectively prevent the harmful toxic gas from intruding into the working surface, and safeguard the safe mining on the working surface.

\section{Data Availability}

The data used to support the findings of this study are available from the corresponding author upon request.

\section{Conflicts of Interest}

The authors declare that they have no conflicts of interest.

\section{Acknowledgments}

The authors gratefully acknowledge the financial support from the National Key Research and Development Program (2018YFC0807900, topic 6), the CCTEG Science and Technology Innovation Fund (Grant no. 2018-2-MS016 and 2018MS015), and the Plan of Social Development and Industrialization Guidance Plan in Liaoning Province (2019JH8/10300099).

\section{References}

[1] Y. G. He, China Coal Outlook 2019, pp. 16-20, China Coal Industry Publishing House, Beijing, China, 2019.
[2] J. R. Wang and G. W. Zhai, Modern Coal Production Technology, pp. 3-32, China Coal Industry Publishing House, Beijing, China, 2012.

[3] W. Wang, "Discussion on spontaneous fire prevention and control in Shendong coal mining area," Safety in Coal Mines, vol. 47, no. 1, pp. 167-169, 2016.

[4] M. G. Yu, F. Teng, T. X. Chu, J. K. Chao, and P. Li, "Simulation study on the evolution of the overlying strata fracture development and air-leaking passage under repeated mining of shallow buried coal seams," Journal of Henan Polytechnic University (Natural Science), vol. 37, no. 1, pp. 1-7, 2018.

[5] J. Deng, B. Li, K. Wang, and C. P. Wang, "Research status and outlook on prevention and control technology of coal fire disaster in China," Coal Science and Technology, vol. 44, no. 10, pp. 1-7, 2016.

[6] Z.-Y. Song, H.-Q. Zhu, B. Tan, H.-Y. Wang, and X.-F. Qin, "Numerical study on effects of air leakages from abandoned galleries on hill-side coal fires," Fire Safety Journal, vol. 69, pp. 99-110, 2014.

[7] Y. 1. Xu, L. Y. Wang, T. X. Chu, and M. G. Yu, "Research progress on coal-fire diffusion and fracture development of coal rocks in coal-fire areas," Journal of Henan Polytechnic University (Natural Science), vol. 32, no. 6, pp. 668-672, 2013.

[8] T. X. Chu and M. G. Yu, S. H. Q. Yang and H. L. Jia, "Air leaking induced by well-developed coal fractures and prevention of spontaneous combustion in goof," Journal of Mining and Safety Engineering, vol. 27, no. 1, pp. 87-93, 2010.

[9] X. X. Miao, "Review of research on mechanical behaviors of mining rock mass and its related engineering technological innovation progress," Chinese Journal of Rock Mechanics and Engineering, vol. 29, no. 10, pp. 1988-1998, 2010.

[10] C. H. Chen and Q. Zhu, "Research advances in formation mechanism of ground crack due to coal mining subsidence in China," Journal of China Coal Society, vol. 43, no. 3, p. 810823, 2018.

[11] R. K. Pan, S. H. G. Cao, Y. Li, and G. D. Li, "Development of overburden fractures for shallow double thick seams mining," Journal of China Coal Society, vol. 43, no. 8, pp. 2261-2268, 2018.

[12] Q. Zeng, D. M. Wang, and Z. H. Y. Cai, "The distribution of fissures/cracks and its permeability with coal fire zones," Journal of China Coal Society, vol. 35, no. 10, pp. 1670-1673, 2010.

[13] G. W. Fan, D. S. H. Zhang, and L. Q. Ma, "Overburden movement and fracture distribution induced by longwall mining of the shallow coal seam in the Shendong coalfield," Journal of China University of Mining and Technology, vol. 40, no. 2, pp. 196-201, 2011.

[14] L. Ma, G. Liu, Y. Xiao, J. H. Lu, and Y. J. He, "Research on multi-field coupling process of coalfield fire area development and evolution," Science and Technology Review, vol. 34, no. 2, pp. 190-194, 2016.

[15] H. Y. Wang, C. H. Feng, L. Geng, B. Yu, X. L. Cui, and M. Z. H. Chen, "Study on air leakage in underground coal fire based on energy level and tracer test," Journal of Safety Science and Technology, vol. 10, no. 1, pp. 118-123, 2014.

[16] W. Jiang, "SF6 tracking technology and energy level detecting combined to detect and measure ventilation leakage in complicated goaf," Coal Science and Technology, vol. 31, no. 8, pp. 9-11, 2003.

[17] B. M. Shi and X. L. Cheng, "Using potential energy measurement and tracing technique to detect air leakage in complicated gob," Mining Safety and Environmental Protection, vol. 29, no. 2, pp. 14-17, 2002. 
[18] G. Wang, R. Wang, M. M. Wu, L. Xin, X. H. Zhou, and C. H. W. Liu, "Prevention and control technology of harmful gas intrusion in close-up coal seam under fire area," Journal of China Coal Society, vol. 42, no. 7, pp. 1765-1775, 2017.

[19] Z. H. Y. Zheng, C. Sang, H. F. Yao, H. J. Wu, and C. H. F. Xu, Y. Q. Liu, "Study of voltage sharing fire preventing and extinguishing under fire area mining in shallow," Coal Mining Technology, vol. 23, no. 1, pp. 73-77, 2018.

[20] J. G. Hao, W. Lu, and J. Xu, "Research on fire prevention technology of coal mining face in shallow depth seam under large air leakage firing zone," Coal Science and Technology, vol. 42, no. 3, pp. 53-56, 2014.

[21] National development and reform commission, Coal Production Technology and Equipment Policy Guidance, pp. 138-146, China Coal Industry Publishing House, Beijing, China, 2014.

[22] W. B. Zhu, J. L. Xu, L. Chen, Z. H. Li, and W. Liu, "Mechanism of disaster induced by in room-and--pillar mining dynamic instability of coal pillar group of shallow and close coal seams," Journal of China Coal Society, vol. 44, no. 2, pp. 358-366, 2019.

[23] T. Wang, W. Zhou, J. Chen, X. Xiao, Y. Li, and X. Zhao, "Simulation of hydraulic fracturing using particle flow method and application in a coal mine," International Journal of Coal Geology, vol. 121, pp. 1-13, 2014.

[24] N. Jan, W. J. Gale, and M. W. Fabjanczyk, "Methods of interpreting ground stress based of underground stress measurements and numerical modelling," in Proceedings of the 2006, Coal Operators' Conference, Wollongong, Australia, July 2006.

[25] D. Y. Cao, X. J. Fan, C. H. Wu, and G. L. Wang, "Study on the fractures related with coalfield fire area in Wuda coalfield, Inner Mongolia," Journal of China Coal Society, vol. 34, no. 8, pp. 1009-1014, 2009.

[26] Z. H. Liu and W. Wang, "Application of instantaneous measurement of radon in the detection of hidden fire sources in small coal pits," Safety in Coal Mines, vol. 48, no. 7, pp. 148-150, 2017.

[27] X. Yi, F. R. Kang, J. Deng, Q. Xiang, and L. Ma, "Research and application on inorganic solidified foam filling material for mine," Journal of Safety Science and Technology, vol. 13, no. 10, pp. 136-142, 2017.

[28] W. Z. H. Guo, Y. F. Jin, and H. T. Li, "Effects of additives properties of high Volume fly ash slurry," Coal Technology, vol. 33, no. 11, pp. 7-10, 2014. 